\title{
The Identification of Polyester Fibers Dyed with Disperse Dyes for Forensic Purposes
}

\author{
Daria Śmigiel-Kamińska ${ }^{1, *(0)}$, Jan Pośpiech ${ }^{1}$, Joanna Makowska ${ }^{1}$, Piotr Stepnowski ${ }^{1}$, \\ Jolanta Wąs-Gubała ${ }^{2}$ and Jolanta Kumirska ${ }^{1, *}$ \\ 1 Faculty of Chemistry, University of Gdańsk, ul. Wita Stwosza 63, 80-308 Gdansk and Poland; \\ pospiechjan@gmail.com (J.P.); joanna.makowska@ug.edu.pl (J.M.); piotr.stepnowski@ug.edu.pl (P.S.) \\ 2 Institute of Forensic Research, Criminalistics Department, Westerplatte 9, 3-033 Krakow, Poland; \\ jwas@ies.krakow.pl \\ * Correspondence: d.smigiel-kaminska@pgdstud.edu.da.pl (D.Ś.-K.); jolanta.kumirska@ug.edu.pl (J.K.); \\ Tel.: +48-58-523-51-93 (D.Ś.K.); +48-58-523-52-12 (J.K.)
}

Received: 28 December 2018; Accepted: 8 February 2019; Published: 10 February 2019

check for updates

\begin{abstract}
In forensic laboratories, the most commonly analyzed microtraces are microscopic fragments of single fibers. One of the main goals of the examination of fragments of fibers a few millimeters long is to determine their characteristic physicochemical properties and compare them with fibers originating from a known source (e.g., a suspect's clothes). The color and dyes of fiber microtraces play an important role in their research and evaluation, being analyzed by means of microscopic, spectroscopic, and chromatographic methods. The results of examinations conducted with the use of spectroscopic techniques might be ambiguous due to overlapping bands of absorption and the transmission and dispersion of electromagnetic radiation corresponding to the specific chemical structure of the fibers and their dyes. For this reason, it is very important to improve currently available spectroscopic methods and/or to propose new ones that allow evidential materials to be analyzed in a much more reliable way. In this review, the possibility of the use of chromatographic techniques with different detection systems for such analyses is underlined. This review covers the different analytical methods used in the forensic analysis of polyester fibers dyed with disperse dyes. Polyester fibers occupy the first position among synthetic fibers in their use for a variety of purposes, and disperse dyes are commonly applied for dyeing them.
\end{abstract}

Keywords: polyester fibers; dyed fibers; disperse dyes; forensic analysis; chromatographic methods; spectroscopic methods

\section{Introduction}

Fibers accompany us every day. Clothing, the upholstery of home and office furniture as well as that of cars, and biomedical materials are produced from fibers, therefore, they can act as a mute witness in a criminal case. Following studies on microtraces in the form of fragments of single fibers, experts from forensic laboratories are able to establish a relationship between individuals, objects, and a crime scene, and sometimes fibers can also help to reconstruct the circumstances of the event. This denotes that even the smallest fragment (e.g., fibers of approx. $0.5 \mathrm{~mm}$ in length with a cross-section of approx. 10 microns) may constitute evidence in a lawsuit. More and more frequently, the analysis of microtraces can explain incidents such as homicides, sexual offenses, robberies, and traffic accidents. The main goal of the identification and comparison of microtraces in the form of fragments of single fibers is to determine their physicochemical properties and then qualify them to a specific type of fiber and assortment of textile products. An important role in the first step of the comparison of such microtraces is played by their color. On the basis of color analysis, evidential fibers can be eligible for 
further study with a comparative material or they are discarded and considered as different from the comparative material.

Because dyes can provide significant information in forensic analyses, many studies have already been carried out to analyze dyes in colored fibers by using diverse microscopical and spectral methods, e.g.,: microspectrophotometry [1-4], Raman spectroscopy [1,5-8], excitation-emission luminescence [9], infrared matrix-assisted laser desorption electrospray [10]; as well as chromatography methods, e.g.,: thin liquid chromatography (TLC) [8,11,12], liquid chromatography (HPLC) with different detectors [12-21], and capillary electrophoresis with a DAD or MS detector [22-28].

Among man-made fibers, polyesters are produced in the greatest amounts (43,301 million metric tons; $75 \%$ of global man-made fiber production in 2012) [26], and disperse dyes are mostly used for dyeing them. For these reasons, single polyester fibers are very often subjected to analysis in forensic laboratories. Unfortunately, there are a limited number of chromatographic methods developed for this purpose [26-28]. There is also no review paper concerning this subject. For this reason, the main aims of this review are as follow: (1) to present the possibility of the application of chromatographic methods for the analysis of polyester fibers dyed with disperse dyes for forensic purposes; (2) to present the possibility of the application of spectroscopic methods for such analyses; (3) to compare a chromatographic approach with a spectroscopic one; (4) to present new challenges in identifying dyed fibers for forensic purposes.

\section{Literature Review Sections}

\subsection{Disperse (Suspension) Dyes in the Textile Industry}

Worldwide production of organic dyes is currently estimated at nearly 450,000 tons. Disperse dyes are low-molecular-weight synthetic organic dyes in the range of 400-600 that represent at least $22 \%$ of the dyes consumed in the world [29-36]. They are marketed in the form of either an easily dispersible powder or a concentrated aqueous dispersion. The Color Index listed around 1150 disperse dyes in 1992 by chemical class, i.e., azo, anthraquinone, meethine, nitrodiphenylamine, xanthene, aminoketone, quinoline, and miscellaneous [29]. Most disperse dyes are essentially planar compounds bearing an azo chromophore attached to polar functional groups such as amine and nitro, and halogens like chlorine or bromine. Color changes are caused by changes in the extent of the delocalization of electrons. More delocalization shifts the absorption max to longer wavelengths and makes the light absorbed redder, while less delocalization shifts the absorption max to shorter wavelengths [36].

Disperse (suspension) dyes are non-ionic substances, practically insoluble in water and in an aqueous solution, and exist in the form of well-dispersed suspension. Disperse dyes in the form of individual molecules penetrate into hydrophobic fibers. It should be noted that these types of dyes may diffuse into the free spaces of a fiber. Such a process is observed when the system exceeds the glass transition temperature. Disperse (suspension) dyes are used for dyeing hydrophobic fibers from cellulose acetate, polyester, and polyamide [29-32].

The classification of disperse dyes by chromogen (Figure 1) is very useful not only for dye chemists but also for forensic analysts. As was mentioned, azo disperse dyes (monoazo and disazo) as well as anthraquinone disperse dyes are the most important classes of disperse dyes in terms of market share, and for this reason, the probability of them being a subject of forensic investigations is the highest. 


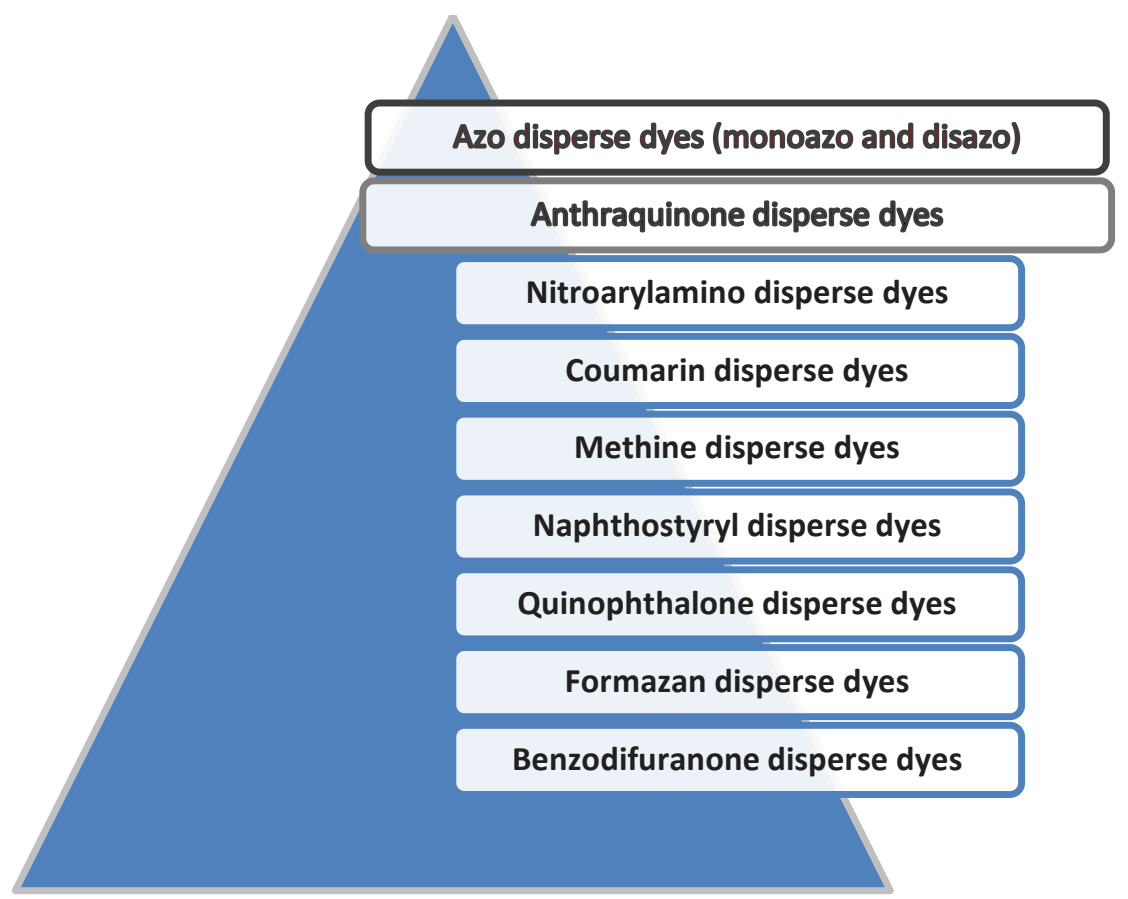

Figure 1. Classification of disperse dyes by chromogen.

\subsection{Extraction of Disperse Dyes from Dyed Textile Fibers for Forensic Purposes}

The extraction method depends directly on the dye class and fiber type [15]. Polyester fibers as well as disperse dyes are hydrophobic [21]. Thus, the best results of extraction should be obtained using solvents characterized by a low polarity, i.e., a small value of a dielectric constant. However, it is also very important to choose a solvent that will not make the experiment difficult at the later stage of the dye identification procedure [12].

Table S1, included in the Appendix, shows methods for the extraction of disperse dyes described in the literature [12-21]. All the studies concerned polyester fibers. A brief description of each extraction procedure shown in Table S1 is presented below.

Method No. 1-Eight different solvents were tested for the extraction of dyes from fibers; the best results were obtained using boiling chlorobenzene [12]. Fibers or small pieces of fabric were introduced into small beakers $(5 \mathrm{~mL})$ or test tubes $(50 \times 6 \mathrm{~mm})$. Next, $0.5-3 \mathrm{~mL}$ of chlorobenzene was added and the samples were put on a hot plate or in an oil bath and boiled for 5 min or until most of the dye had been extracted [12].

Method No. 2-Two alternative extraction solvents were used: chlorobenzene and dimethylformamide (DMF). In the first case, a single 2-5 mm-long fiber was pushed to the bottom of a $5 \mathrm{~cm}$ length of glass capillary tubing and $5 \mu \mathrm{L}$ of chlorobenzene was added. The tube with fibers was sealed and heated at $100{ }^{\circ} \mathrm{C}$ for $15 \mathrm{~min}$. The extract was evaporated to dryness by heating at $100{ }^{\circ} \mathrm{C}$ for $30 \mathrm{~min}$ and the residue was dissolved in $5 \mu \mathrm{L}$ of HPLC mobile phase [13]. In the second case, the fibers were introduced into tubes and extracted using $4 \mu \mathrm{L}$ of a mixture of dimethylformamide (DMF) and acetonitrile $(\mathrm{ACN})(1: 1, v / v)$. The dimethylformamide had been previously modified by the addition of $1.25 \mathrm{~g}$ of 2,6-di-tert-butyl-4-methylphenyl and $1 \mathrm{~g}$ of citric acid to each $250 \mathrm{~mL}$ of solvent. The unsealed tubes were agitated by hand for $1-2 \mathrm{~min}$ in a silicone oil bath at $120-130^{\circ} \mathrm{C}$. After cooling, $6 \mu \mathrm{L}$ of mobile phase was added to the samples [13].

Method No. 3-Nine disperse dyes were extracted from $10 \mathrm{~cm}$ or less single polyester fibers. The fibers were placed in a capillary tube and $5 \mu \mathrm{L}$ of chlorobenzene was added. The sealed tube was heated in an oven to $130{ }^{\circ} \mathrm{C}$ for $30 \mathrm{~min}$. After this time, the fiber was removed and the extract was evaporated to dryness. The dry residue was dissolved in $15 \mu \mathrm{L}$ of acidified acetonitrile containing an internal standard at a concentration of $1 \mathrm{ng}$ per $5 \mu \mathrm{L}$ injection [14]. 
Method No. 4-A single fiber of $10 \mathrm{~mm}$ in length was subjected to extraction. The extraction was carried out for fiber discoloration but for not longer than $2 \mathrm{~h}$ [15].

Method No. 5-Single filaments of a length of $0.5 \mathrm{~mm}, 2 \mathrm{~mm}$, and $5 \mathrm{~mm}$ were extracted in Waters Total Recovery ${ }^{\circledR}$ liquid vials at $100{ }^{\circ} \mathrm{C}$ for $1 \mathrm{~h}$. After extraction, the solvent was evaporated to dryness at $90{ }^{\circ} \mathrm{C}$. The dried residue was dissolved in $50 \mu \mathrm{L}$ of methanol $(\mathrm{MeOH})$ and $50 \mathrm{mM}$ ammonium acetate at $\mathrm{pH} 4.5$ [16].

Method No. 6-During this study, nine disperse dyes were isolated from single polyester fibers (5 $\mathrm{mm}$ in length) or from polyester thread (7 $\mathrm{mm}$ in length). Based on diode array detector data, dimethylformamide (DMF) was found to be a more effective extraction solvent than acetonitrile/water $(4: 3, v / v)$ or methanol/water $(1: 1, v / v)$ mixtures [17].

Method No. 7-Standardized fibers of a length of $20 \mathrm{~mm}$ were extracted in plugged glass capillaries [18].

Method No. 8 - $0.5 \mathrm{~g}$ of cut polyester fabric was subjected to extraction using $5 \mathrm{~mL}$ of solvent; the procedure was repeated, and the obtained extracts combined. The extraction was carried out in glass tubes using an ultrasonic bath. The extracts were evaporated to dryness under a stream of nitrogen and then dissolved in $1 \mathrm{~mL}$ of methanol and filtered [19].

Method No. 9-Single fibers of $10 \mathrm{~mm}$ in length were extracted using $20 \mu \mathrm{L}$ of dimethylsulfooxide (DMSO) at $100{ }^{\circ} \mathrm{C}$ to discoloration or for a maximum of $2 \mathrm{~h}$ [20].

Method No. 10 - Single 0.5 -cm polyester fibers were extracted in a sealed glass capillary using $20 \mu \mathrm{L}$ of acetonitrile. Extraction was initiated using ultrasonication for $5 \mathrm{~min}$, then the sample was heated in a water bath at $60{ }^{\circ} \mathrm{C}$ for $60 \mathrm{~min}$. After centrifugation, the obtained extracts were ready for HPLC-MS/MS analysis [21].

According to the presented above data [12-21], solvents commonly used for the extraction of disperse dyes from polyester fibers are as follow: chlorobenzene, methanol $(\mathrm{MeOH})$, acetonitrile $(\mathrm{ACN})$, dimethylsulfooxide (DMSO), and dimethylformamide (DMF) (Figure 2). The highest value of the dielectric constant of the presented solvents is for DMSO ( 46.7) and the lowest for chlorobenzene ( 9). The other remaining solvents, i.e., $\mathrm{MeOH}$, can, and DMF, are similar, taking into account the polarity of the system $(\sim<33-37>)$.

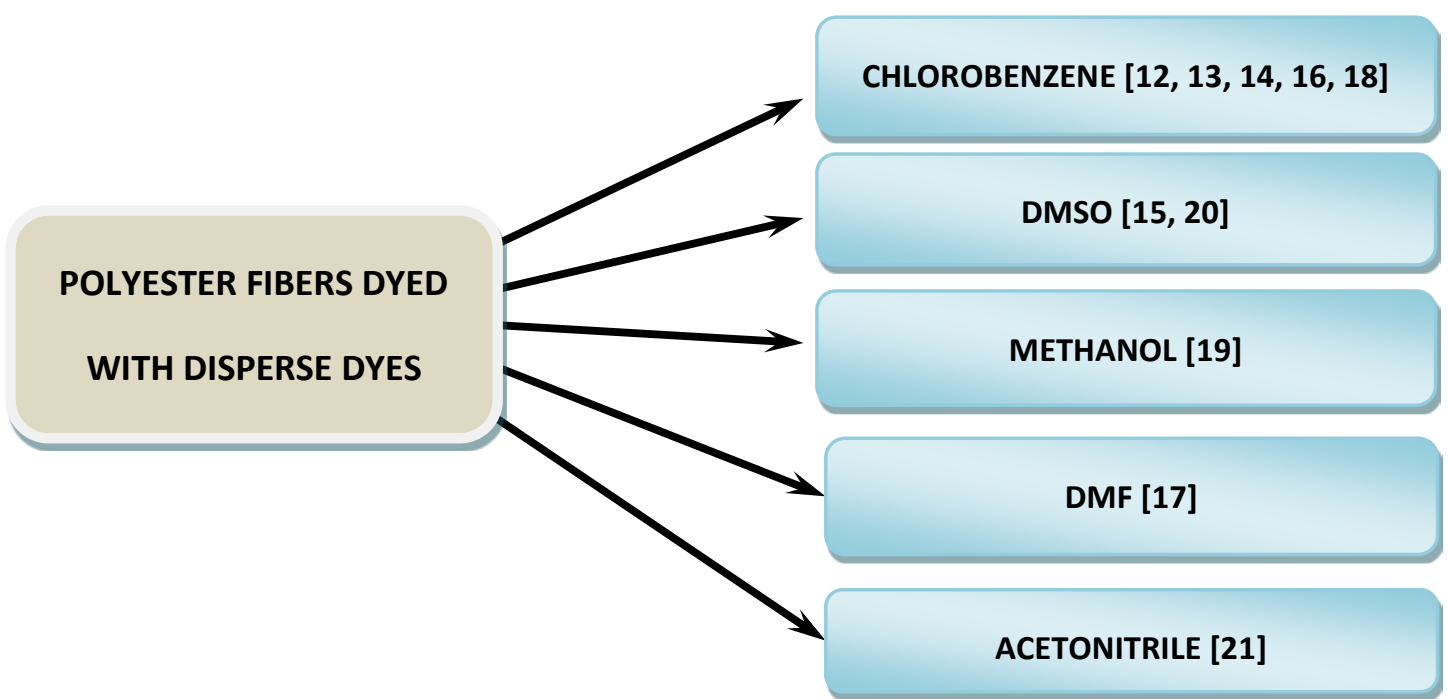

Figure 2. Solvents applied for the extraction of disperse dyes from dyed polyester fibers.

The most commonly used solvent for this purpose is chlorobenzene [12-14,16,18] (Figure 2; Table S1). Extraction was carried out for fibers or small pieces of fibers in the range of length 2-20 nm [12-14,16,18]. Depending on the fiber size and temperature of extraction, the required volume of chlorobenzene varied from $5 \mu \mathrm{L}[13,14]$ to $0.5-3.0 \mathrm{~mL}[12]$. 
The extractions were carried out at high temperatures: $100{ }^{\circ} \mathrm{C}[13,16] ; 130{ }^{\circ} \mathrm{C}[14,18]$, or at the boiling point of chlorobenzene $\left(\mathrm{t}=138^{\circ} \mathrm{C}\right)$ [12]. The extraction time at $100{ }^{\circ} \mathrm{C}$ was both $15 \mathrm{~min}$ [13] and $60 \mathrm{~min}$ [16], at $130^{\circ} 10 \mathrm{~min} \mathrm{[18]} \mathrm{or} 30 \mathrm{~min}$ [14], and at the boiling point of chlorobenzene, the process was continued for $5 \mathrm{~min}$ or until most of the dyes had been extracted [12].

DMSO [15,20], MeOH [19], DMF [17], and ACN [21] as pure solvents were also found to be suitable for extraction of disperse dyes from colored polyester fibers. Depending on the type of disperse dyes and the amount of material, time and temperature of extraction was different.

In the case of DMSO, $10 \mathrm{~mm}$ pieces of fiber were submerged in $20 \mu \mathrm{L}$ of solvent and heated to $100{ }^{\circ} \mathrm{C}$ until the fiber was discolored or for a maximum of $2 \mathrm{~h}[15,20]$. Only in the case of one dye named Disperse Blue 73, the time was slightly shorter than $2 \mathrm{~h} \mathrm{[15].}$

For experiments performed using $\mathrm{MeOH}$ as an extractant (5.0 mL of $\mathrm{MeOH} ; 0.5 \mathrm{~g}$ cut fabric), the temperature must achieve max. $70{ }^{\circ} \mathrm{C}$ (this is the lower temperature in comparison to $100{ }^{\circ} \mathrm{C}$ for DMSO), and the process should be continued for $15 \mathrm{~min}$ and repeated in the same conditions [19]. A mixture $\mathrm{MeOH} /$ water $(1: 1, v / v)$ was not as effective as DMF for the extraction of disperse dyes from colored fibers [17].

For extraction using DMF, $30 \mu \mathrm{L}$ of solvent was placed with a textile thread in a glass capillary tube and a sample was heated at $100{ }^{\circ} \mathrm{C}$ in a heat block [17].

As mentioned above, ACN could be used as a pure solvent [21] or as a component of the extraction mixture [17] of disperse dyes. Pure ACN was applied for the extraction of the $0.5 \mathrm{~cm}$ piece of polyester fiber [21], while a mixture of $\mathrm{ACN}: \mathrm{H}_{2} \mathrm{O}(4: 3, v / v)$ for the extraction of the length of fiber $5 \mathrm{~mm}$ or $7 \mathrm{~mm}$ (tread) [17]. In the case of a mixture of $\mathrm{ACN}: \mathrm{H}_{2} \mathrm{O}$, the sample was heated at $100{ }^{\circ} \mathrm{C}$ for $30 \mathrm{~min}$, and in the case of pure solvent $(\mathrm{ACN})$, the extraction was initiated using ultrasonication for $5 \mathrm{~min}$ followed by heating in a water bath at $60^{\circ} \mathrm{C}$.

In summary, there is no universal solvent for the extraction of disperse dyes from polyester fibers. However, due to chlorobenzene being used the most often for such extractions, this solvent should be the first one tested by analysts planning such an experiment, before any of the other above-mentioned solvents. Optimization of the extraction procedure is crucial for further identification of dyes.

\subsection{Identification of Dyed Textile Fibers for Forensic Purposes Based on Chromatographic Techniques}

The methods currently used for forensic analyses should allow the analysis of individual fibers of 5 to $10 \mathrm{~mm}$ in length [18]. Such small amounts of the sample contain 2 to $200 \mathrm{ng}$ of dye [18]. Therefore, analytical methods for identification must be sensitive enough to be able to detect such an amount of dye. Tables S2 and S3 included in the Supplementary show the methods developed for the identification of disperse dyes based on chromatographic techniques [12-21]. A description of the chromatographic conditions is included in Table S2 and the selected qualification and quantification parameters in Table S3. A general scheme of identification of disperse dyes extracted from colored polyester fibers for forensic purposes based on chromatographic techniques is presented in Figure 3.

The most commonly described chromatographic technique used for this purpose is high-performance liquid chromatography (HPLC) coupled with different types of spectrophotometric detectors: (UV-Vis) [12,13]; linear diode array (LDA) [13], photodiode-array (PDA) [14], diode array (DAD) [15-18,20], as well coupled with mass spectrometric (MS) [18], and high resolution mass spectrometric (HRMS) $[15,20]$ and tandem mass spectrometric (MS/MS) detectors $[17,21]$. In many cases HPLC-MS apparatus contains both detection systems $[15,17,18]$. The most frequently used chromatographic column is the reverse-phase C18 column $[13,18,21]$ whose length is from $50 \mathrm{~mm}$ to $1150 \mathrm{~mm}$. Other types of chromatographic columns are: ODS-2 with length $150 \mathrm{~mm}[14,17]$ and ODS-5 with length $150 \mathrm{~mm}$ [15]. In one case, chromatographic analysis was performed using a LiCrosorb Si-60 column [12]. All chromatographic separation of disperse dyes was carried out under gradient conditions and with application of different mobile phases (water:MeOH with ammonium acetate $[15,17,20]$, water:acetonitrile acidified [13,14], water:acetonitrile [18], acetic acid in water:acetic acid in acetonitrile [21], and hexane:ethyl acetate [12]). The time of analysis was from $20 \mathrm{~min}$ to $67 \mathrm{~min}$. 
The mobile phase flow rate was from $0.2 \mathrm{~mL} / \mathrm{min}$ to $1 \mathrm{~mL} / \mathrm{min}$ with an injection volume of $5 \mu \mathrm{L}$ or $10 \mu \mathrm{L}$.

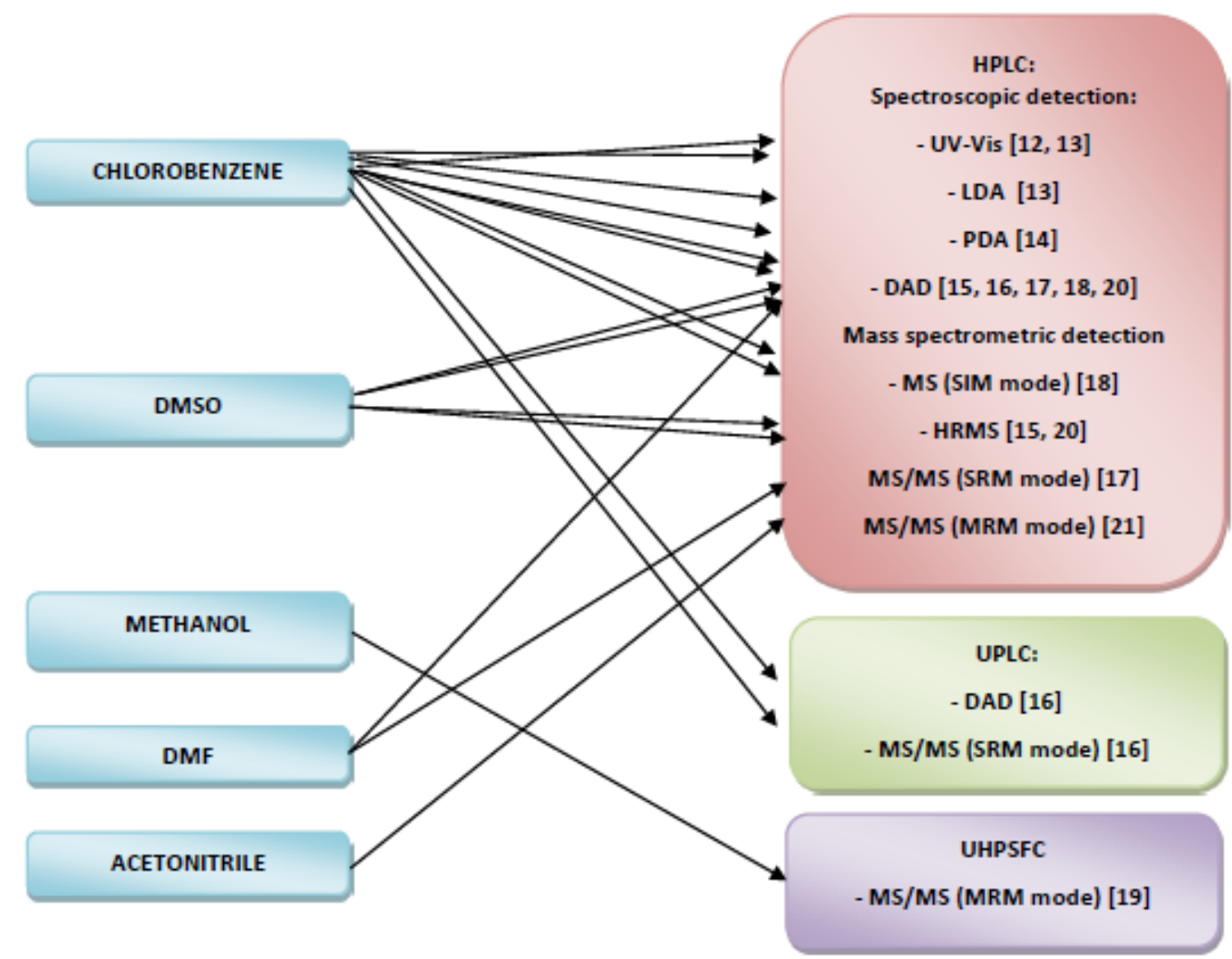

Figure 3. Chromatographic methods applied for the analysis of disperse dyes in extracts.

Another chromatographic technique used for the identification of disperse dyes extracted from polyester fibers is ultra-performance liquid chromatography (UPLC) coupled with DAD (a wavelength range from 325 to $675 \mathrm{~nm}$ ) and MS/MS detectors [16]. The separation was performed using a column $\mathrm{C} 18$ with length $50 \mathrm{~mm}$. The analysis was carried out under gradient conditions; methanol with $0.15 \%$ formic acid and $50 \mathrm{mM}$ ammonium acetate were used as the mobile phases. The time of analysis was $6.5 \mathrm{~min}$, the mobile phase flow rate was from $0.6 \mathrm{~mL} / \mathrm{min}$ and $0.3 \mathrm{~mL} / \mathrm{min}$ (it was dependent on the type of detector), and the volume of injection was $10 \mu \mathrm{L}$ [16].

Identification of disperse dyed extracted from polyester fibers was also performed using ultra-high-performance supercritical fluid chromatography coupled with tandem mass spectrometry technique (UHPSFC-MS/MS) [19]. In order to select the optimum stationary phase, four different chromatography columns (BEH, BEH2-ethylpyridine, HSSC18 SB and CSH fluorophenyl) were tested. The results showed that the best separation efficiency and the highest sensitivity were achieved using Waters ACQUITY UPC2 тм BEH C18 columns. As mobile phases $\mathrm{MeOH}(\mathrm{A})$ and $\mathrm{CO}_{2}(\mathrm{~B})$ were used. The time of analysis was $4.5 \mathrm{~min}$. The flow rate was $2 \mathrm{~mL} / \mathrm{min}$, while the injection volume was $1 \mu \mathrm{L}[19]$.

As mentioned, the chromatographic methods used for forensic analyses should allow the identification of individual fibers based on 2 to $200 \mathrm{ng}$ of dye [18]. Therefore, knowledge about qualification and quantification parameters is also very important.

John C. West extracted and analyzed 18 disperse dyes on polyester textiles using TLC and HPLC (Tables S2 and S3, Method No. 1) [12]. Signals were registered at 420, 500, and 600 nm wavelengths. A comparison of both chromatographic approaches showed that the HPLC method gave slightly better 
resolution and better sensitivity, and consequently, smaller amounts of dyes could be examined and trace components could be easily observed. Moreover, poorly visible colors in TLC were visible in HPLC when the appropriate wavelength was chosen. Using the HPLC method, the differentiation of two dyes with the same $\mathrm{R}_{\mathrm{f}}$ value in TLC was possible. Thus, the HPLC method was better than TLC [12].

The separated dyes could be monitored either using a single wavelength filter photometer or a multi-wavelength linear diode array detector (Tables S2 and S3) [13]. Identification of 57 disperse dyes extracted from dyed polyester fibers was based on retention parameters. Minimum detection levels of $200 \mathrm{pg}$ of injected dye were obtained with both systems. These levels were 10-20 times those obtained with dye extracts originating from fibers of 2-5 $\mathrm{mm}$ in length, although for very light shades the sensitivity was only just adequate. This method, based on the extraction of 2-5 $\mathrm{mm}$ of single fibers, provided the discrimination of all fibers examined [13].

For the separation and characterization of acid, basic, and disperse dyes, Speers and co-workers used a gradient elution HPLC system with an end-capped narrow-bore reversed phase column and photodiode-array detection (Tables S2 and S3, Method No. 3) [14]. Standard commercial dyes were used for the optimization procedure. Spectral data of the standard commercial dyes (including nine disperse dyes) separated using the HPLC system, together with their relative retention times with respect to Rhodamine B, were stored in a library created using Millennium PDA software. Basic and disperse dyes extracted from $10 \mathrm{~mm}$ fibers were qualitatively and quantitatively identified using a database of relative retention times and the spectral data of standard commercial dyes. The system exhibited good reproducibility, efficiency, and sensitivity [14].

The identification of dyes extracted from fibers dyed with Disperse Blue 73 (Tables S2 and S3, Method 4) was based on retention times, and the mass accuracy (deviation generally $<2$ ppm) was recorded using a high-resolution MS detector [15]. In addition, for each standard solution of dye and for each dye extracted from a fiber, the absorption spectrum was recorded using a DAD detector. The absorption spectra were compared using special software that determined the spectrum match index of a standard solution of dye with the spectrum of a dye extracted from the sample. If the index was more than 800 , they considered the spectra to be quite similar, indicating that this is probably the same substance. If the index was above 900 , the spectra were recognized as almost identical, ensuring that the standard and analyte are the same compound. The limits of detection (LODs) were shown as the minimum concentration of dissolved dye powder $(\mu \mathrm{g} / \mathrm{L})$ and the minimum fiber length required to identify the dye. The LOD values established using the DAD detector were $50.7 \mu \mathrm{g} / \mathrm{L}$ and $0.14 \mathrm{~mm}$, while for the MS detector they were $1.1 \mu \mathrm{g} / \mathrm{L}$ and $0.003 \mathrm{~mm}$, respectively [15].

Hoy, in his work [16], compared the results of identification and quantification of nine dyes, among them three belonging to the disperse class (Violet 77, Disperse Blue 60, Disperse Yellow 114) extracted from single fibers of 0.5, 1, and $5 \mathrm{~mm}$ in length (Tables S2 and S3, Method No. 5). Disperse Violet 77 and Disperse Yellow 114 dyes were detected and identified in all fibers while Disperse Blue 60 was detectable only in 1 and $5 \mathrm{~mm}$ fibers. Compared to other dye classes, the detection limits for disperse dyes were higher. The detection limit for these dyes ranged from 0.99 to $12.60 \mathrm{ppb}$ for calibration concentrations from 10 to $50 \mathrm{ppb}$, except for Disperse Blue 60, for which it was $50 \mathrm{ppb}$. The DAD detector turned out to be more sensitive than MS-MS, probably due to the incorrect selection of ionization conditions [16].

Identification of nine disperse dyes isolated from polyester fibers ( $5 \mathrm{~mm}$ in length) was based on the retention times of isolated dyes and the selected reaction monitoring data (SRM) (Tables S2 and S3, Method No. 6). The LOD values were significantly lower than the amount of dye present in the protected fiber. The LOD values ranged from 1 to $15 \mathrm{pg}$ for the linear ion trap tandem mass spectrometric detector (LIT-MS/MS) and from 750 to $1750 \mathrm{pg}$ for the DAD detector [17].

The identification of dyes extracted from fibers from the upholstery of various car models was based, e.g., on the chromatograms and mass spectra (Tables S2 and S3, Method No. 7). Dorrien identified the Disperse Red 4 dye isolated from a standardized $20 \mathrm{~mm}$ fiber [18]. 
The identification of 17 disperse dyes isolated from the fabric samples was based on retention times and $m / z$ values of parent/quantitative/assistant qualitative daughter ions (Tables S2 and S3, Method No. 8). The dye recovery from the fabric samples ranged from $70 \%$ to $103 \%$. The detection limits were in the range of 0.02 to $1 \mu \mathrm{g} / \mathrm{mL}$ [19].

Schotman and co-workers developed Method No. 9 (Tables S2 and S3) for the analysis of dye in forensic fibers and textile examination on case examples [20]. Seven cases and a quality assurance test are presented. In these cases, the fibers or textiles submitted for investigation were analyzed using HPLC-DAD-MS to identify the dyes present. The results show that a mixture of dyes is present in all the textiles investigated except one sample that was taken from a manufacturer's dye shade card. It is concluded that dye analysis improves the evidential value of forensic fiber examinations as it becomes possible to distinguish textiles that are different in dye chemistry but have a similar color. In addition, dye analysis makes the examination more robust as it becomes possible to attribute color differences between samples to identical dyes (mixed in different ratios) or to chemically different dyes [20].

The last method (Method No. 10, Tables S2 and S3), developed by Hu and co-workers [21], allowed a forensic fiber examination to be performed of 11 dyes representing five different classes of dyes, among them four disperse dyes (Disperse Yellow 9, Disperse Red 1, Disperse Violet 26 and Disperse Brilliant Red). Under the optimized conditions, the limit of detection (LOD) for disperse dyes reached 0.01-1.0 ng/mL in Multi Reaction Monitor (MRM) mode. This method allowed single fibers with a length of a few millimeters or less to be analyzed, which makes it suitable for forensic analysis.

Taking into account all the data presented above, it should be noticed that chromatographic methods have a great potential for the identification of polyester fibers dyed with disperse dyes for forensic purposes. Qualification and quantification parameters of such methods could be significantly improved by optimization of chromatographic conditions in HPLC/UPLC/UHPSFC systems and/or by application of more selective and sensitive detectors (UV-Vis $<$ LDA $<$ PDA $<$ DAD, MS(SIM) $<$ HRMS $<$ MS /MS(SRM) $<$ MS/MS(MRM). Extraction of disperse dyes from colored polyester fibers should also be performed in optimal conditions.

\subsection{Identification of Dyed Textile Fibers for Forensic Purposes Based on Spectroscopic Techniques}

During recent years, the application of spectroscopic techniques to the identification and discrimination of textile fibers has gradually increased. Microspectrophotometry in the ultraviolet-visible range (UV-VIS MSP), Raman spectroscopy, and Fourier transformed infrared spectroscopy (RS and FTIR, respectively), are the main spectroscopic techniques used for this purpose. At the same time, technology continues improving (ATR, MIR, DRIFTS) and other spectroscopic techniques can be applied in this forensic area for textile analysis (for example, inductively coupled plasma atomic emission spectroscopy-ICP-AES or X-ray fluorescence spectroscopy-XFS [37]). There are several factors that explain the increased interest in spectroscopic techniques for the study of textile fibers. These techniques are non-destructive and require only a very small amount of sample to develop an analysis. Moreover, they involve easy sample preparation and allow on-site and quick microscopic exams in a short time. Since the laser beam is around 0.8 micrometers, it can even be applied for the measurement of microfibers presented in the current market [38].

The use of spectroscopic techniques for the forensic analysis of textile fibers was presented by Pablo Prego Meleiro and Carmen García-Ruiz in their review paper from 2016 [38]. Nevertheless, a limited number of publications concerning the analysis of colored fibers dyed using disperse dyes was found in the literature $[2,4,10,12]$.

The study of polyester fibers dyed with ternary mixtures of disperse dyes in small mass concentrations, as well as the analysis of the disperse dyes alone using spectroscopic techniques (RS and UV-VIS MSP) was performed [2]. Three types of excitation sources, 514, 633, and $785 \mathrm{~nm}$, were used during RS examinations, while the UV-VIS MSP study was conducted in the 200 to $800 \mathrm{~nm}$ range. Analyzing the obtained results, it was observed that the He-Ne laser $(k=633 \mathrm{~nm})$ turned out to be the least effective in measurements of the Raman spectra of disperse dyes (no spectrum for 
$50 \%$ of samples). Application of a $785 \mathrm{~nm}$ line of excitation allowed for an increase in the amount of interpretable Raman spectra to $75 \%$. Using a $514 \mathrm{~nm}$ wavelength laser for measurements made it possible to obtain the Raman spectra of all of the disperse dyes examined, in which $42 \%$ were good quality. Obtained results led to the conclusion that none of the lasers used was ideal for the study of disperse dyes, but in spite of that the majority of them were differentiated using RS [2].

The same parameters of RS were used for the analysis of fibers from the polyester fabrics dyed with ternary mixtures of disperse dyes [2]. Analysis showed that a wavelength of $633 \mathrm{~nm}$ was completely ineffective for these samples because no spectra were obtained. The application of a wavelength of $514 \mathrm{~nm}$ produced good quality spectra for $50 \%$ of the samples but a wavelength of $785 \mathrm{~nm}$ was necessary to achieve good quality spectra for all polyester fiber samples. Spectra for dyed and undyed polyester fibers and spectra for dyes used were evaluated in terms of estimating the possibility of identifying each dye from the ternary mixture. An analysis of the results for a wavelength of $785 \mathrm{~nm}$ showed that bands from fiber-forming polymer (PET) were dominant in the spectra of dyed fibers. From all of the dyes, only one at the highest concentration could be identified (level of dye concentration in the dye bath amounted to $0.18 \%$ ). In the same case, when wavelengths of $514 \mathrm{~nm}$ and $633 \mathrm{~nm}$ were used, good quality spectra were not obtained, mainly caused by the fluorescence [2].

Results of the study of polyester fibers carried out using UV-Vis MSP indicated strong absorption of ultraviolet light by the fiber-forming polymer. Those results led to the conclusion that this type of testing should first be carried out in the range of visible light and ultraviolet A radiation (above $310 \mathrm{~nm}$ ). The UV-Vis MSP method also showed limited possibilities for discriminatory analysis of slightly dyed polyester fibers dyed with a mixture of disperse dyes.

The authors demonstrated that the capabilities for the discernment of polyester fibers dyed with ternary mixtures of disperse dyes were similar for both the spectroscopic methods employed-RS and UV-Vis MSP [2].

Today, UV-Vis MSP remains the most efficient method and the recommended analytical technique for the routine study of textile fibers in the forensic field [2-4,24]. It is the most used and the most discriminating spectroscopic technique available for the study of textile fibers, being an indispensable method for the objective evaluation and comparison of fiber colors. It should be also underlined that RS has become a good new tool in forensic studies of textile fibers, with a clear high potential to detect and identify dyes in fibers. On the other hand, FTIR spectroscopy shows a greater capacity for studying polymeric substrates compared with the study of dyes and is the recommended method for the identification of the classes and subclasses of the polymeric matrix. Co-monomers, solvents, and additives can be identified using FTIR, which allows further discrimination between the subclasses, for example of acrylic fibers [2,4,38].

In recent years, developments in Raman instrumentation, particularly regarding the juxtaposition of a spectrometer and optical microscope, have made this technique more attractive for analytical use. RS has been deemed the only technique through which molecular structural information concerning the dye present in a fiber may be obtained in a virtually nondestructive manner [2,4]. RS and FTIR spectroscopy are complementary techniques and a frequent recommendation, in order to obtain a comprehensive analysis of textile fibers for forensic purposes, is a combination of both techniques. On the other hand, new and informative analytical techniques are emerging for the analysis of textile fibers as microtraces related with a crime scene, but their application in the analysis of colored polyester fibers dyed using disperse dyes has not yet been presented.

\section{Comparison of Chromatographic Methods for the Identification of Dyed Textile Fibers for Forensic Purposes with a Spectroscopic Approach}

Both chromatographic (often associated with mass spectrometric detection) and spectroscopic techniques are used in forensic examination for the identification of dyed textile fibers.

Chromatographic techniques are destructive; however, they can give detailed information about the dyes of textile fibers. The identification of dyes is based not only on retention times but often on 
mass spectra or the selected, characterized $\mathrm{m} / \mathrm{z}$ values of dyes. This method creates an opportunity for a comparison between dyes from the evidence and competitive dyes. It is also possible to determine the chemical structure of the dyes.

Spectroscopic techniques are non-destructive but give spectra including information derived from fiber polymers, dyes, or fiber polymers and dyes. The obtained data depend on the applied spectroscopic technique (RS, UV-Vis MSP, or FTIR) and measurement conditions. It should be emphasized that the mentioned methods are complementary and none of them are perfect.

The time of preparation of a sample and the time of its analysis is longer using chromatographic than spectroscopic techniques. In chromatographic techniques, the preparation of a sample requires the use of additional reagents and some special equipment, but the parameters of the analysis of individual types of dyes are constant. The identification of dyes is based on chromatographic (retention times) and mass spectrometric ( $m / z$ values) data.

In spectroscopic techniques, the fiber is treated as a sample but the analysis conditions must be determined individually.

In the forensic laboratory, microtraces of dyed textile fibers are examined usually by optical and sometimes electronic microscopy. Optical microscopy allows the identification of textile fibers based on the characteristics of their physicochemical structure. Optical research is concentrated mainly on stereoscopic microscopy with reflected light, biological microscopy with transmitted light, polarized light microscopy, UV light, and fluorescence microscopy. In this part of the examination, a scanning electron microscope can be used, especially to study damage to textile fibers.

It should be noted that the first step of studies on microtraces of dyed textile fibers is always the same. After the selection of samples and testing by optical microscopy, further methods have to be chosen for research, and this usually depends on the research laboratory equipment.

As mentioned, both chromatography and spectroscopy methods have advantages and disadvantages regarding the identification and comparison of dyed textile fibers. Therefore, the further choice of experimental methods depends on many reasons, e.g., type, form, and volume of evidence and equipment of the research lab.

\section{New Challenges in Identifying Dyed Fibers for Forensic Purposes}

Nowadays, there are many new challenges for scientists involved in the analysis and identification of textile fibers. They are directly related to the technological progress that is taking place in the modern world, and consequently, the creation of new materials and dyes for their coloring. These trends have been described, among others, by Tatsuya Hongu and Glyn O. Phillips in the book entitled "New Millennium Fibers" [39]. The authors classify newly formed fibers as "superfibers" or "new frontier fibers". Their development is determined by the desire of the world to achieve two objectives. The first is to improve human health and to increase the comfort of life. The second is to improve the quality of medical care and to emphasize the use of nanotechnology in the creation of various nano-fibers. Furthermore, the increase in the share of renewable raw materials, derived from agro-culture, in the synthesis of polymers presents new challenges [39]. The fibers produced from these materials will have a different chemical composition than the fibers produced from petroleum compounds, which could potentially influence the analysis and identification of the fibers. Designing alternative, fast, and relatively inexpensive methods, using the analytical techniques available in forensic labs, will be extremely valuable for new analytical problems in this area [11].

At present, however, the old methods are usually used during the analysis of fibers secured as evidential material at crime scenes. Microscopy dominates this field by offering a wide range of analyses. In combination with other analytical techniques, it is the most important tool for fiber identification and comparison. Microscopy should be the first choice for any fiber researcher.

However, it is important to use and optimize new and more informative analytical techniques for the analysis of textile fibers as traces related with crime scenes, such as infrared chemical imaging 
spectroscopy, X-ray fluorescence, and metal underlayer ATR spectroscopy (MU-ATR), as well as chromatographic techniques with different detection systems [11-21,40].

Any kind of damage sustained by a textile product through use, lowering its aesthetic and practical value, is disadvantageous from the user's as well as the producer's perspective. However, forensic material that has some sort of characteristic damage can have greater evidential value. For this reason, research into the destructive processes that act on a textile product in the course of its use, or damage due to the effects of specific chemical and physical factors, is important from a forensic standpoint as well, since it can help in the process of ascertaining the course of events and circumstances of a crime [40]. This is why it is important to continue research into new destructive agents that give each textile fiber its individual character.

\section{Conclusions}

The discrimination of fiber samples is crucial for forensic scientists throughout the world and the research methods in this field should be developed in order to minimize the possibility of mistakes. This review sheds new light on both suspension (disperse) dyes and dyed polyester fibers, and their identification using chromatographic techniques with different detection systems. The presentation of chromatographic procedures, and the comparison of their usefulness with spectroscopic approaches, allows the identification of which analytical method is best suited for the effective characterization of polyester fibers dyed with disperse dyes. This knowledge could help formulate the correct forensic expertise without the risk of mistakes.

Supplementary Materials: The following are available online, Tables S1-S3. Table S1: Overview of the extraction procedures of disperse dyes from dyed polyester fibers; Table S2: Overview of chromatographic methods described in the literature [12-21] for the identification of disperse dyes extracted from polyester fibers (chromatographic conditions); Table S3: Overview of chromatographic methods described in the literature [12-21] for the identification of disperse dyes extracted from polyester fibers (selected qualification and quantification parameters).

Author Contributions: This article was jointly written by and proof-read by all authors. All authors contributed in various degrees to the review.

Funding: This research was funded by The Ministry of Science and Higher Education, grant number 538-8610-B800-18 and DS 530-8616-D593-18.

Acknowledgments: We acknowledge support by the Ministry of Science and Higher Education under grant nos. 538-8610-B800-18 and DS 530-8616-D593-18.

Conflicts of Interest: The authors declare no conflict of interest.

\section{References}

1. Robertson, J.; Grieve, M. (Eds.) Forensic Examination of Fibers, 2nd ed.; Taylor \& Francis: Abingdon, UK, 1999; ISBN-10: 0748408169.

2. Wąs-Gubała, J.; Starczak, R. Nondestructive Identification of Dye Mixtures in Polyester and Cotton Fibers Using Raman Spectroscopy and Ultraviolet-Visible (UV-Vis) Microspectrophotometry. Appl. Spectrosc. 2015, 69, 296-303. [CrossRef] [PubMed]

3. Was-Gubała, J.; Starczak, R. UV-Vis microspectrophotometry as a method of differentiation between cotton fiber evidence coloured with reactive dyes. Spectrochim. Acta A 2015, 142, 118-125. [CrossRef] [PubMed]

4. Reichard, E.J.; Bartick, E.G.; Morgan, S.L.; Goodpaster, J.V. Microspectrophotometric analysis of yellow polyester fiber dye loadings with chemometric techniques. Anal. Chem. 2017, 3, 21-27. [CrossRef]

5. Buzzini, P.; Massonnet, G. The Analysis of Colored Acrylic, Cotton, and Wool Textile Fibers Using Micro-Raman Spectroscopy. J. Forensic Sci. 2015, 60, 712-720. [CrossRef] [PubMed]

6. Was-Gubała, J.; Machnowski, W. Application of Raman spectroscopy for differentiation among cotton and viscose fibers dyed with several dye classes. Spectrosc. Lett. 2014, 47, 527-535. [CrossRef]

7. Zaffino, Ch.; Bruni, S.; Guglielmi, V.; De Luca, E. Fourier-transform surface-enhanced Raman spectroscopy (FT-SERS) applied to the identification of natural dyes in textile fibers: An extractionless approach to the analysis. J. Raman Spectrosc. 2014, 45, 211-218. [CrossRef] 
8. Brust, H.; van der Weerd, I.J.; Kok, W.T. Discriminating Cotton Fibers: Analysis of Dyes using Extraction, TLC and Raman Spectroscopy; Project Netherlands Forensic Institute (NFI) Department of Fibers \& Textiles: Hague, The Netherlands, 2009.

9. Appalaneni, K.; Heider, E.C.; Moore, A.F.T.; Campiglia, A.D. Single Fiber Identification with Nondestructive Excitation-Emission. Anal. Chem. 2014, 86, 6774-6780. [CrossRef]

10. Cochran, K.H.; Barry, J.A.; Muddiman, D.C.; Hinks, D. Direct analysis of textile fabrics and dyes using infrared matrix-assisted laser desorption electrospray ionization mass spectrometry. Anal. Chem. 2013, 85, 831-836. [CrossRef]

11. Houck, M.M. Identyfication of Textile Fibers, 1st ed.; Woodhead Publishing: Cambridge, UK, 2009; ISBN-10: 1845692667.

12. West, J.C. Extraction and analysis of disperse dyes on polyester textiles. J. Chromatogr. 1981, $208,4754$. [CrossRef]

13. Wheals, B.B.; White, P.C.; Paterson, M.D. High-performance liquid chromatographic method utilising single or multi-wavelength detection for the comparison of disperse dyes extracted from polyester fibers. J. Chromatogr. 1985, 350, 205-2015. [CrossRef]

14. Speers, S.J.; Little, B.H.; Roy, M. Separation of acid, basic and dispersed dyes by a single-gradient elution reversed-phase high-performance liquid chromatography system. J. Chromatogr. A 1994, 674, 263-270. [CrossRef]

15. Carey, A.; Rodewijk, N.; Xu, X.; Van Der Weerd, J. Identification of dyes on single textile fibers by HPLC-DAD-MS. Anal. Chem. 2013, 85, 11335-11343. [CrossRef] [PubMed]

16. Hoy, S.J. Development and Figures of Merit of Microextraction and Ultra-Performance Liquid Chromatography for Forensic Characterization of Dye Profiles on Trace Acrylic, Nylon, Polyester, and Cotton Textile Fibers. Ph.D. Thesis, University of South Carolina, Portland, OR, USA, 2013.

17. Kato, T.; Suzuki, Y.; Handa, M. Extraction and Analysis of Disperse Dyes from Colored Polyester Single Fibers Using Liquid Chromatography/Linear Ion Trap Tandem Mass Spectrometry. Anal. Sci. 2016, 32, 1019-1022. [CrossRef] [PubMed]

18. Dorrien, D.M. Discrimination of Automobile Carpet Fibers Using Various Analytical Techniques and the Subsequent Creation of a Comprehensive Database. Ph.D. Thesis, University of Central Florida, Orlando, FL, USA, 2006.

19. Zhou, Y.; Du, Z.; Zhang, Y. Simultaneous determination of 17 disperse dyes in textile by ultra-high performance supercritical fluid chromatography combined with tandem mass spectrometry. Talanta 2014, 127, 108-115. [CrossRef] [PubMed]

20. Schotman, T.G.; Xiu, X.; Rodewijk, N.; van der Weerd, J. Application of dye analysis in forensic fibre and textile examination: Case examples. Forensic Sci. Int. 2017, 278, 338-350. [CrossRef] [PubMed]

21. Hu, C.; Zhu, J.; Mei, H.; Shi, H.; Guo, H.; Zhang, G.; Wang, P.; Lu, L.; Zheng, X. A sensitive HPLC-MS/MS method for the analysis of fiber dyes. Forensic Chem. 2018, 11, 1-6. [CrossRef]

22. Morgan, S.; Vann, B.; Baguley, B.; Stefan, A. Advances in discrimination of dyed textile fibers using capillary electrophoresis/mass spectrometry. In Proceedings of the Trace Evidence Symposium, Clearwater Beach, FL, USA, 13-16 August 2007.

23. Stefan, A.R.; Dockery, C.R.; Baguley, B.M.; Vann, B.C.; Nieuwland, A.A.; Hendrix, J.E.; Morgan, S.L. Microextraction, capillary electrophoresis, and mass spectrometry for forensic analysis of azo and methine basic dyes from acrylic fibers. Anal. Bioanal. Chem. 2009, 394, 2087-2094. [CrossRef]

24. Stefan, A.R.; Dockery, C.R.; Nieuwland, A.A.; Roberson, A.R.; Baguley, B.M.; Hendrix, J.E.; Morgan, S.L. Forensic analysis of anthraquinone, azo, and metal complex acid dyes from nylon fibers by micro-extraction and capillary electrophoresis. Anal. Bioanal. Chem. 2009, 394, 2077-2085. [CrossRef]

25. Dockery, C.R.; Stefan, A.R.; Nieuwland, A.A.; Roberson, A.R.; Baguley, B.M.; Hendrix, J.E.; Morgan, S.L. Automated extraction of direct, reactive and vat dyes from cellulosic fibers for forensic analysis by capillary electrophoresis. Anal. Bioanal. Chem. 2009, 394, 2095-2103. [CrossRef]

26. Farah, S.; Kunduru, K.R.; Tsach, T.; Bentolila, A.; Domb A., J. Forensic comparison of synthetic fibers. Polym. Adv. Technol. 2015, 26, 785-796. [CrossRef]

27. Goodpaster, J.V.; Liszewski, E.A. Forensic analysis of dyed textile fibers. Anal Bioanal Chem. 2009, 394, 2009-2018. [CrossRef] [PubMed] 
28. Beldean-Galea, M.S.; Copaciu, F.-M.; Coman, M.-V. Chromatographic Analysis of Textile Dyes. J. AOAC Int. 2018, 101, 1353-1370. [CrossRef] [PubMed]

29. Koh, J. Dyeing with Disperse Dyes. In Textile Dyeing; Hauser, P.J., Ed.; InTechOpen: Winchester, UK, 2011; ISBN-10: 9789533075655; Available online: https:/ / www.intechopen.com/books/textile-dyeing/dyeingwith-disperse-dyes (accessed on 25 November 2018). [CrossRef]

30. Aspland, J.R. Disperse Dyes and Their Application to Polyester. Textile Chem. Color. 1992, 24, 18-23.

31. Joonseok, K.; Hoegyeong, K.; Jieun, L.; Minyoung, E. Dyeing and fastness properties of phthalimide-based alkali-clearable azo disperse dyes on poly(ethylene terephthalate). Color. Technol. 2009, 125, 322-327. [CrossRef]

32. Heinrich, Z. Color Chemistry, Syntheses, Properties and Applications of Organic Dyes and Pigments, 2nd ed.; VCH Publishing: Weinheim, Germany, 1991; ISBN-10: 3527262008.

33. David, L. Coloration for the next century. Rev. Prog. Color. 1999, 29, 23-28. [CrossRef]

34. Stolz, A. Basic and applied aspects in the microbial degradation of azo dyes. Springer Verlage 2001, 56, 69. [CrossRef]

35. Li, X.Q.; Zhang, Q.H.; Ma, K.; Li, H.M.; Guo, Z. Identification and determination of 34 water-soluble synthetic dyes in foodstuff by high performance liquid chromatography-diode array detection-ion trap time-of-flight tandem mass spectrometry. Food Chem. 2015, 182, 316-326. [CrossRef]

36. Abd-Alreha, L.; Al-Rubaie, R.; Jameel Mhessn, R. Synthesis and Characterization of Azo Dye Para Red and New Derivatives. Eur. J. Chem. 2012, 9, 465-470. [CrossRef]

37. Nakashima, H.; Ooshima, T. Analysis of Inorganic Antimicrobial Agents in Antimicrobial Products: Evaluation of a Screening Method by X-ray Fluorescence Spectrometry and the Measurement of Metal by Inductively Coupled Plasma Atomic Emission Spectroscopy. J. Health Sci. 2007, 53, 423-429. [CrossRef]

38. Meleiro, P.P.; Garcia-Ruiz, C. Spectroscopic techniques for the forensic analysis of textile fibers. Appl. Spectrosc. Rev. 2016, 51, 278-301. [CrossRef]

39. Hongu, T.; Machiko, T.; Phillips, G.O. New Millennium Fibers, 1st ed.; CRC Press: Boca Raton, FL, USA, 2005; ISBN-10:0849325986.

40. Wass-Gubała, J. Selected Aspects of the Forensic Examination of Textile Traces. Fibres Text. East. Eur. 2009, 17, $26-29$.

Sample Availability: Samples of the compounds are not available from the authors.

(C) 2019 by the authors. Licensee MDPI, Basel, Switzerland. This article is an open access article distributed under the terms and conditions of the Creative Commons Attribution (CC BY) license (http://creativecommons.org/licenses/by/4.0/). 